\title{
Environmental Contaminants in Hospital Settings and Progress in Disinfecting Techniques
}

\author{
Gabriele Messina, ${ }^{1}$ Emma Ceriale, ${ }^{2}$ Daniele Lenzi, ${ }^{3}$ Sandra Burgassi, ${ }^{1}$ \\ Elena Azzolini, ${ }^{2}$ and Pietro Manzi ${ }^{3}$ \\ ${ }^{1}$ Laboratory of Environmental Hygiene, University of Siena, Italy \\ ${ }^{2}$ Post Graduate School in Public Health, University of Siena, Italy \\ ${ }^{3}$ Teaching Hospital "Le Scotte," Hospital Direction, Siena, Italy
}

Correspondence should be addressed to Gabriele Messina; gabriele.messina@unisi.it

Received 30 April 2013; Accepted 17 September 2013

Academic Editor: Marc Léone

Copyright (C) 2013 Gabriele Messina et al. This is an open access article distributed under the Creative Commons Attribution License, which permits unrestricted use, distribution, and reproduction in any medium, provided the original work is properly cited.

Medical devices, such as stethoscopes, and other objects found in hospital, such as computer keyboards and telephone handsets, may be reservoirs of bacteria for healthcare-associated infections. In this cross-over study involving an Italian teaching hospital we evaluated microbial contamination (total bacterial count (TBC) at $36^{\circ} \mathrm{C} / 22^{\circ} \mathrm{C}$, Staphylococcus spp., moulds, Enterococcus spp., Pseudomonas spp., E. coli, total coliform bacteria, Acinetobacter spp., and Clostridium difficile) of these devices before and after cleaning and differences in contamination between hospital units and between stethoscopes and keyboards plus handsets. We analysed 37 telephone handsets, 27 computer keyboards, and 35 stethoscopes, comparing their contamination in four hospital units. Wilcoxon signed-rank and Mann-Whitney tests were used. Before cleaning, many samples were positive for Staphylococcus spp. and coliforms. After cleaning, CFUs decreased to zero in most comparisons. The first aid unit had the highest and intensive care the lowest contamination $(P<0.01)$. Keyboards and handsets had higher TBC at $22^{\circ} \mathrm{C}(P=0.046)$ and mould contamination $(P=0.002)$ than stethoscopes. Healthcare professionals should disinfect stethoscopes and other possible sources of bacterial healthcare-associated infections. The cleaning technique used was effective in reducing bacterial contamination. Units with high patient turnover, such as first aid, should practise stricter hygiene.

\section{Introduction}

The Centre for Disease Control (CDC) defines a healthcare-associate infections (HAIs) as a "localized or systemic condition resulting from an adverse reaction to the presence of an infectious agent(s) or its toxin(s). There must be no evidence that the infection was present or incubating at the time of admission to the acute care setting." HAIs may be caused by infectious agents from endogenous (body sites) or exogenous sources (patient care personnel, visitors, patient care equipment, medical devices, or the health care environment) [1]. Every year, millions of people across the world suffer from HAIs. HAIs are a wide-ranging concern in the medical field, not only because of morbidity and the possibly of lethal consequences for patients, but also because of extended hospital stays and associated high costs [2-5].
In Europe HAIs cause 16 million extra days of hospital stay and 37000 attributable deaths; they determine approximately costs associated of $€ 7$ billion annually. In the USA around 99000 deaths were attributed to HAIs in 2002 and associated costs were approximately US $\$ 6.5$ billion in $2004[5,6]$.

A Europe-wide point prevalence survey estimated that at least 2.6 million cases of HAI occur annually in long-term care facilities, in addition to ECDC's earlier estimated at 4.1 million patients acquiring HAIs in acute-care hospitals [7].

These infections often have little or nothing to do with the primary reason for the hospital visit but are a result of poor or inadequate hygiene in the healthcare setting [8]. Healthcare equipment is frequently shared between hospital staff, who may have different hygiene practices. Medical devices (stethoscopes, otoscopes, and thermometers) and various objects in hospital environments, such as telephones 
and computers, have been associated with transmission of HAIs [9-18]. Stethoscopes/phonendoscopes (stethoscopes) are medical devices frequently used in direct contact with patients' skin and can therefore be a vector of infections. These occurrences are known to the scientific community and testified by numerous international studies [9, 11, 16-18]. Physicians should disinfect stethoscopes between one patient and another, though unfortunately this good practice is not always implemented.

Computers and telephones are now tools of medical practice and are found in all healthcare settings. Their disinfection is often neglected more than that of medical devices. Several studies demonstrate major contamination of these objects and a possible role in the transmission of infection $[13,15]$. Current scientific knowledge suggests that the disinfection of environmental surfaces in modern hospitals is indispensable. Furthermore other simple measures, such as hand hygiene of medical staff, remain of a great impact to avoid HAIs [19]. Various studies have investigated singly the role of stethoscopes, computer keyboards, and telephone handsets in HAIs $[9-13,15,16]$. To our knowledge there is lack of research on the evaluation of all these devices together, in different units of the same hospital, where there should be a specific organizational model and risk factors [8] with regard to HAIs. The aims of the present study were to evaluate (i) the contamination of stethoscopes, computer keyboards, and telephone handsets in an Italian teaching hospital before and after use of a disinfecting technique (DT); (ii) differences in contamination in four hospital units; (iii) differences in contamination of medical devices used in clinical practice (stethoscopes) and tools used in medical practice (computer keyboards and telephone handsets).

\section{Materials and Methods}

2.1. Setting. We conducted a cross-over study in an Italian teaching hospital with 750 beds in Siena. A variety of hospital environments [8] were chosen to consider different characteristics: "emergency unit" and "first aid" which have a high turnover of patients and disinfection of the environment cannot always be pursued effectively, "intensive care" which observe aseptic conditions and most patients are at high risk of developing infections, and "cardiology/hemodynamic" which are medical units and have rooms with more beds than the intensive care unit and are frequented by many visitors.

Before the study began, meetings were held between the hospital management and the principal researcher. This is was necessary to explain the project, establish the necessary contacts and avoid any bias in conducting the study. It was considered important to avoid bias caused by doctors/nurses knowing when the investigation would be run, as this might prompt changes in hygiene. It was also decided that stethoscope sampling would be on the same day in each unit, to prevent news of the study circulating and modifying hygienic practices.

2.2. Disinfecting Technique. We conducted a surface challenge test to determine the capacity of the disinfectant in killing bacteria and mould [20]. For the cleaning and disinfection of these objects we used a putty compound having a malleable elastic consistency that adheres, removing dirt and disinfecting at the same time. These two characteristics distinguish this disinfecting technique from traditional methods of cleaning and disinfection, aspects normally achieved using two separate operations. The main sanitizing principle of the putty is ethanol $(29 \%)$ and other components are purified water $(51 \%)$, guar $(6 \%)$, glycerine $(7 \%)$, and minor quantities of other substances, such as boric acid, colorants, and odorants. These features make the putty particularly useful for cleaning and disinfecting surfaces with indentations and protrusions, such as keyboards and handsets. The technique disinfects, as demonstrated by studies conducted according to the indications of the U.S. Pharmacopeial Convention (USP), Chapter 〈1072〉 "Disinfectants and antiseptic" and according to CONFARMA protocol number 229100911 A$\mathrm{B}$ which is based on (i) guidelines of the Germany Society for Hygiene and Microbiology 1991, (ii) European standards EN 1040 "Chemical disinfectants and antiseptics-Basic bactericidal activity_-Test method and requirements (phase 1)," and (iii) EN 13697 "Chemical disinfectants and antisepticsQuantitative non-porous surface test for evaluation of bacteria and/or fungicidal activity of chemical disinfectants used in food, ind ustrial, domestic and institutional areas-Test method and requirements without mechanical action (phase 2/step 2)" [21].

2.3. Data Collection. It was decided to study almost all the stethoscopes, computer keyboards, and telephone handsets found in the four units. We analysed 99 objects: 37 telephone handsets, 27 computer keyboards, and 35 stethoscopes (including shared and nonshared ones).

The experimental protocol required a first sample (swab) $\mathrm{H}(0)$ from one-half of each stethoscope membrane, keyboard, and telephone handset, before cleaning with the putty, and a second sample $\mathrm{H}(1)$ from the other half of the same objects after cleaning. The swab $\mathrm{H}(0)$ was necessary to evaluate the initial contamination level [20]. Samples were obtained by swabbing the surfaces with sterile cotton pads for approximately 5 seconds per stethoscope, 20-30 per keyboard, and 15-20 per telephone. These swabbing times were established according to the different size of the objects. Cleaning half of the stethoscope diaphragm, computer keyboard, and telephone handset with the product took about 20-25 seconds, 2-4 minutes and 20-30 seconds, respectively, depending on dirtiness.

Taking samples, at $\mathrm{H}(0)$ and $\mathrm{H}(1)$, from both halves of the stethoscopes, keyboards, and telephone handsets was important to avoid the possibility that the first swabs removed bacteria physically, reducing the amount of bacteria collected by the second swab from the same surface and preventing true assessment of product efficacy in reducing bacterial/mould contamination. Because the two halves of the keyboard are different and some keys are used more than others (e.g., "enter") we decided to alternate the side to which the product was applied. 
All doctors/nurses encountered during the visit to the units were informed by the principal researcher/hospital management doctor of the study and were asked if there was any problem about carrying out the study; there were no objections. A new pack of product was used for every object. The following information was also recorded at the time of sampling: hospital identification (ID), department ID, and doctor/nurse ID. Records were indexed with a unique ID for each sample. The same ID was assigned to the pack of cleaning putty. All the information was recorded and stored in a database for future analysis.

2.4. Laboratory Analysis. Analysis was carried out in the Hygiene and Environmental Laboratory of the University of Siena, where the swabs were placed in $1 \mathrm{~mL}$ phosphate buffered saline, shaken in a vortex mixer and the liquid sown $(0.1 \mathrm{~mL} /$ plate $)$ in Petri dishes containing plate count agar (PCA) for total microbial load incubating at $36^{\circ} \mathrm{C}$ for mesophilic germs (human contamination) and at $22^{\circ} \mathrm{C}$ for psychrophilic microorganisms (environmental contamination). Index microorganisms were cultured in mannitol salt agar for Staphylococcus spp. (hand-transmitted pathogens), Pseudomonas cetrimide for Pseudomonas spp. faecal contamination), Slanetz \& Bartley medium for Enterococcus spp. (faecal contamination), Brilliance E. coli/coliform spp. chromogenic medium for Escherichia coli and coliform bacteria (faecal contamination), Acinetobacter base for Acinetobacter spp. (an emerging alert for HAIs), and Brilliance methicillinresistant Staphylococcus aureus (MRSA) MRSA2 medium for methicillin-resistant Staphylococcus aureus incubating at $36^{\circ} \mathrm{C}$ (Staphylococcus aureus resistant to methicillin antibiotics). Clostridium difficile agar base was supplemented with Clostridium difficile selective supplement and 7\% defibrinated horse blood for Clostridium difficile spp. (as an indicator of poor disinfection) with incubation for 48 hours at $36^{\circ} \mathrm{C}$ in an anaerobiosis jar. Anaerobiosis was obtained using a gas generating kit.

All the sowings were made by the same technician of the Department of Physiopathology, Experimental Medicine and Public Health involved in the study. The Petri dishes were read by the principal researcher and the technician. The results were expressed as colony-forming units per swab $(\mathrm{CFU} / 0.1 \mathrm{~mL})$. The plates were read 24 and 48 hours after sowing. We opted for a double count: at 24 hours to prevent vigorous bacterial growth from rendering some colonies uncountable at 48 hours and at 48 hours to avoid missing bacterial species/colonies with slower growth. All bacteria/mould counts were added to the previous database for further use.

2.5. Statistical Analysis. Database cleaning was performed before data analysis. Descriptive analysis (mean, standard deviation, median, interquartile range, minimum, and maximum) of the data for all types of microbes/moulds was performed for $\mathrm{H}(0)$ and $\mathrm{H}(1)$. For each bacterium, we counted the number of positive samples for $\mathrm{H}(0)$ and $\mathrm{H}(1)$ and calculated their percentages. We also calculated the total quantitative CFU count of the 99 objects for $\mathrm{H}(0)$ and $\mathrm{H}(1)$ and the percentage reduction after use of the experimental disinfecting technique. The matched approach used (two halves of each object, one before and one after cleaning) aimed at better control of confounders, minimizing their effects and increasing the reliability of the results. When CFUs of $\mathrm{H}(1)$ were not zero, statistical tests were carried to highlight differences between before and after cleaning. Descriptive analysis for $\mathrm{H}(0)$ was also conducted at ward level to determine contamination load. To reveal differences in bacterial contamination before and after use of the product the Wilcoxon signed-rank test was used, while the MannWhitney test was used to detect differences (i) between units, (ii) between telephone handsets plus computer keyboards versus stethoscopes, and (iii) between personal and shared stethoscopes [22].

Significance was set at $P<0.05$. Stata SE, version 12.1 software (StataCorp, College Station, TX, USA), was used for the analysis.

\section{Results}

Descriptive statistics are shown in Table 1. Mean, median, interquartile range, and standard deviation were obtained considering only positive samples. The percentage of positive $\mathrm{H}(0)$ samples was generally higher on computer keyboards, followed by telephone handsets and stethoscopes. The only exception was MRSA, where the latter had a higher percentage of positive samples: $28.6 \%$ compared to $16.2 \%$ for telephone handsets and $22.2 \%$ for computer keyboards.

No $\mathrm{H}(0)$ or $\mathrm{H}(1)$ samples contained Pseudomonas or Clostridium difficile (only investigated on stethoscopes). CFUs decreased to zero in most comparisons.

For stethoscopes, significant CFU differences were detected in PCA 36, PCA22, Staphylococcus spp. $(P<$ $0.0001)$, E. coli $(P=0.025)$, Coliforms $(P=0.0001)$, MRSA $(P=0.002)$, and Enterococcus spp. $(P=0.046)$. For the latter, only four samples were positive before cleaning. No CFU differences emerged for moulds $(P<0.563)$; only 2 stethoscopes were contaminated with moulds before cleaning and one after cleaning.

For computer keyboards we found CFU differences before and after cleaning for PCA 36, PCA22, Coliforms, Staphylococcus spp., moulds $(P<0.0001)$, E. coli $(P=0.001)$, Enterococcus spp. $(P=0.045)$ and MRSA $(P=0.014)$. One keyboard $\mathrm{H}(0)$ sample was contaminated with Acinetobacter spp.

No significant differences were identified in the distribution of telephone handsets, computer keyboards and stethoscopes in the 4 wards $\left(P=0.325\right.$, Fisher's exact $\left.X^{2}\right)$.

For telephone handsets, significant differences in CFUs were highlighted for PCA36, PCA22, Coliforms, Staphylococcus spp. $(P<0.0001)$, and MRSA $(P=0.008)$. Six telephone handsets were contaminated with moulds before cleaning and one still after cleaning.

Our results showed that the highest CFU counts came from the "first aid" unit and the lowest ones from the "intensive care" unit. Differences between these two units were significant for all bacterial species $(P<0.01)$. Table 2 
TABle 1: Descriptive statistics of stethoscopes, computer keyboards, and telephone handsets at $\mathrm{H}(0)$ and $\mathrm{H}(1)$ : number and percentage of positive samples, overall CFUs counts and percentage reduction in CFUs from $\mathrm{H}(0)$ to $\mathrm{H}(1)$, means, standard deviations, medians, interquartile ranges (IQR), minima, and maxima.

\begin{tabular}{|c|c|c|c|c|c|c|c|c|c|}
\hline Object & Culture medium ${ }^{*}$ & Time & $\begin{array}{c}\text { Positive } \\
\text { sample (\%) }\end{array}$ & $\begin{array}{l}\text { CFU total } \\
\text { count }^{\mathrm{b}}\end{array}$ & $\%$ reduction & $\operatorname{Mean}^{\mathrm{a}}(\mathrm{SD})$ & Median $^{\mathrm{a}}$ (IQR) & $\operatorname{Min}^{\mathrm{a}}$ & Max \\
\hline \multirow{16}{*}{$\begin{array}{l}\text { Stethoscopes } \\
(n=35)\end{array}$} & \multirow{2}{*}{ TBC 36} & $\mathrm{H}(0)$ & $20(57.1)$ & 3368 & \multirow{2}{*}{-99.97} & $168.4(304.7)$ & 19 (7.5 to 188$)$ & 1 & 1110 \\
\hline & & $\mathrm{H}(1)$ & $1(2.9)$ & 1 & & $1(-)$ & $1(1)$ & 1 & 1 \\
\hline & \multirow{2}{*}{ TBC 22} & $\mathrm{H}(0)$ & $22(62.9)$ & 3678 & \multirow{2}{*}{-100} & $167.2(367)$ & 9.5 (5 to 55$)$ & 1 & 1508 \\
\hline & & $\mathrm{H}(1)$ & $0(0)$ & 0 & & $-(-)$ & $-(-)$ & - & - \\
\hline & \multirow{2}{*}{ E. coli } & $\mathrm{H}(0)$ & $5(14.3)$ & 123 & \multirow{2}{*}{-100} & $24.6(30)$ & 11 (3 to 37$)$ & 1 & 71 \\
\hline & & $\mathrm{H}(1)$ & $0(0)$ & 0 & & $-(-)$ & $-(-)$ & - & - \\
\hline & \multirow{2}{*}{ Coliforms } & $\mathrm{H}(0)$ & $15(42.9)$ & 1009 & \multirow{2}{*}{-100} & $67.2(120)$ & $6(3$ to 62$)$ & 1 & 361 \\
\hline & & $\mathrm{H}(1)$ & $0(0)$ & 0 & & $-(-)$ & $-(-)$ & - & - \\
\hline & \multirow{2}{*}{ Enterococci } & $\mathrm{H}(0)$ & $4(11.4)$ & 14 & \multirow{2}{*}{-100} & $3.5(4.4)$ & $1.5(1$ to 6$)$ & 1 & 10 \\
\hline & & $\mathrm{H}(1)$ & $0(0)$ & 0 & & $-(-)$ & $-(-)$ & - & - \\
\hline & \multirow{2}{*}{ Staphylococci } & $\mathrm{H}(0)$ & $21(60)$ & 2605 & \multirow{2}{*}{-100} & $124.1(270)$ & $10(5$ to 70$)$ & 2 & 1003 \\
\hline & & $\mathrm{H}(1)$ & $0(0)$ & 0 & & $-(-)$ & $-(-)$ & - & - \\
\hline & \multirow{2}{*}{ MRSA } & $\mathrm{H}(0)$ & $10(28.6)$ & 130 & \multirow{2}{*}{-100} & $13(16)$ & $5(2$ to 21$)$ & 1 & 50 \\
\hline & & $\mathrm{H}(1)$ & $0(0)$ & 0 & & $-(-)$ & $-(-)$ & - & - \\
\hline & \multirow{2}{*}{ Moulds } & $\mathrm{H}(0)$ & $2(5.7)$ & 2 & \multirow{2}{*}{-50} & $1(-)$ & $1(1)$ & 1 & 1 \\
\hline & & $\mathrm{H}(1)$ & $1(2.9)$ & 1 & & $1(-)$ & $1(1)$ & 1 & 1 \\
\hline \multirow{16}{*}{$\begin{array}{l}\text { Telephone } \\
\text { handsets } \\
(n=37)\end{array}$} & \multirow{2}{*}{ TBC 36} & $\mathrm{H}(0)$ & 33 (89.2) & 645 & \multirow{2}{*}{-99.22} & $20(30)$ & 11 (4 to 25$)$ & 1 & 156 \\
\hline & & $\mathrm{H}(1)$ & $3(8.12)$ & 5 & & $1.7(0.6)$ & 2 (1 to 2$)$ & 1 & 2 \\
\hline & TBC 22 & $\mathrm{H}(0)$ & 33 (89.2) & 580 & 79 & $18(28.5)$ & $6(2$ to 22$)$ & 1 & 152 \\
\hline & & $\mathrm{H}(1)$ & $4(10.8)$ & 7 & -90.19 & $1.8(1.5)$ & 1 (1 to 2.5$)$ & 1 & 4 \\
\hline & E coli & $\mathrm{H}(0)$ & $1(2.7)$ & 1 & -100 & $1(-)$ & $1(1)$ & 1 & 1 \\
\hline & L. corl & $\mathrm{H}(1)$ & $0(0)$ & 0 & -100 & $-(-)$ & $-(-)$ & - & - \\
\hline & Coliforms & $\mathrm{H}(0)$ & $22(59.5)$ & 194 & & $8.8(7.8)$ & $8(2$ to 12$)$ & 1 & 30 \\
\hline & Congotitis & $\mathrm{H}(1)$ & $1(2.7)$ & 1 & & $1(-)$ & $1(1)$ & 1 & 1 \\
\hline & Enterococci & $\mathrm{H}(0)$ & $2(5.4)$ & 2 & -100 & $1(-)$ & $1(1)$ & 1 & 1 \\
\hline & & $\mathrm{H}(1)$ & $0(0)$ & 0 & -100 & $-(-)$ & $-(-)$ & - & - \\
\hline & Stanhylococci & $\mathrm{H}(0)$ & $31(83.8)$ & 427 & -9953 & $13.8(22.4)$ & $6(2$ to 14$)$ & 1 & 99 \\
\hline & & $\mathrm{H}(1)$ & $2(5.4)$ & 2 & & $1(-)$ & $1(1)$ & 1 & 1 \\
\hline & MRSA & $\mathrm{H}(0)$ & 7 (18.9) & 23 & - & $3.3(2.8)$ & 3 (1 to 4$)$ & 1 & 9 \\
\hline & VINUת & $\mathrm{H}(1)$ & $0(0)$ & 0 & -10 & $-(-)$ & $-(-)$ & - & - \\
\hline & Moulds & $\mathrm{H}(0)$ & $6(16.2)$ & 14 & 78.57 & $2.3(2.4)$ & 1 (1 to 3$)$ & 1 & 7 \\
\hline & & $\mathrm{H}(1)$ & $1(2.7)$ & 3 & -70.37 & $3(-)$ & $3(3)$ & 3 & 3 \\
\hline & TBC 36 & $\mathrm{H}(0)$ & $26(96.3)$ & 512 & 41 & $19.7(16.6)$ & 14 (8 to 33$)$ & 1 & 66 \\
\hline & & $\mathrm{H}(1)$ & $2(7.4)$ & 3 & & $1.5(0.7)$ & 1.5 (1 to 2$)$ & 1 & 2 \\
\hline & TBC 22 & $\mathrm{H}(0)$ & $25(92.6)$ & 557 & & $22.3(15.2)$ & 21 (9 to 31$)$ & 1 & 57 \\
\hline & $10 \mathrm{C} 2 \mathrm{Z}$ & $\mathrm{H}(1)$ & $4(14.8)$ & 18 & & $4.5(5.7)$ & 2 (1.5 to 7.5$)$ & 1 & 13 \\
\hline & E coli & $\mathrm{H}(0)$ & $11(40.7)$ & 16 & & $1.5(0.7)$ & 1 (1 to 2$)$ & 1 & 3 \\
\hline & L. coil & $\mathrm{H}(1)$ & $0(0)$ & 0 & 100 & $-(-)$ & $-(-)$ & - & - \\
\hline Computer & Coliforms & $\mathrm{H}(0)$ & $21(77.8)$ & 147 & -96.60 & $7(6.5)$ & 5 (3 to 9$)$ & 1 & 27 \\
\hline keyboards & & $\mathrm{H}(1)$ & $2(7.4)$ & 5 & 90.00 & $2.5(2.1)$ & $2.5(1$ to 4$)$ & 1 & 4 \\
\hline$(n=27)$ & Enterococci & $\mathrm{H}(0)$ & $4(14.8)$ & 4 & 0 & $1(-)$ & $1(1)$ & 1 & 1 \\
\hline & Linetococet & $\mathrm{H}(1)$ & $0(0)$ & 0 & & $-(-)$ & $-(-)$ & - & - \\
\hline & Staphylococci & $\mathrm{H}(0)$ & $25(92.6)$ & 239 & & $9.6(9)$ & 5 (4 to 12$)$ & 1 & 37 \\
\hline & & $\mathrm{H}(1)$ & $1(3.7)$ & 1 & 97.50 & $1(-)$ & $1(1)$ & 1 & 1 \\
\hline & MRSA & $\mathrm{H}(0)$ & $6(22.2)$ & 27 & -100 & $4.5(3)$ & 4.5 (2 to 6$)$ & 1 & 9 \\
\hline & ИКМА & $\mathrm{H}(1)$ & $0(0)$ & 0 & -100 & $-(-)$ & $-(-)$ & - & - \\
\hline & Moulds & $\mathrm{H}(0)$ & $20(74.1)$ & 137 & -99.27 & $6.9(8)$ & 3.5 (1.5 to 9$)$ & 1 & 29 \\
\hline & & $\mathrm{H}(1)$ & $1(3.7)$ & 1 & & $1(1)$ & $1(1)$ & 1 & 1 \\
\hline
\end{tabular}

${ }^{*} 1 \mathrm{CFU}$ of Acinetobacter was found only in one keyboard at $\mathrm{H}(0)$; TBC 36 and $\mathrm{TBC} 22$, respectively, are total microbial load incubating at $36^{\circ} \mathrm{C}$ and $22^{\circ} \mathrm{C}$; MRSA: methicillin-resistant Staphylococcus aureus; ${ }^{a}$ only positive samples; ${ }^{\mathrm{b}}$ summing all CFUs per stethoscopes, computer keyboards, and telephone handsets. 


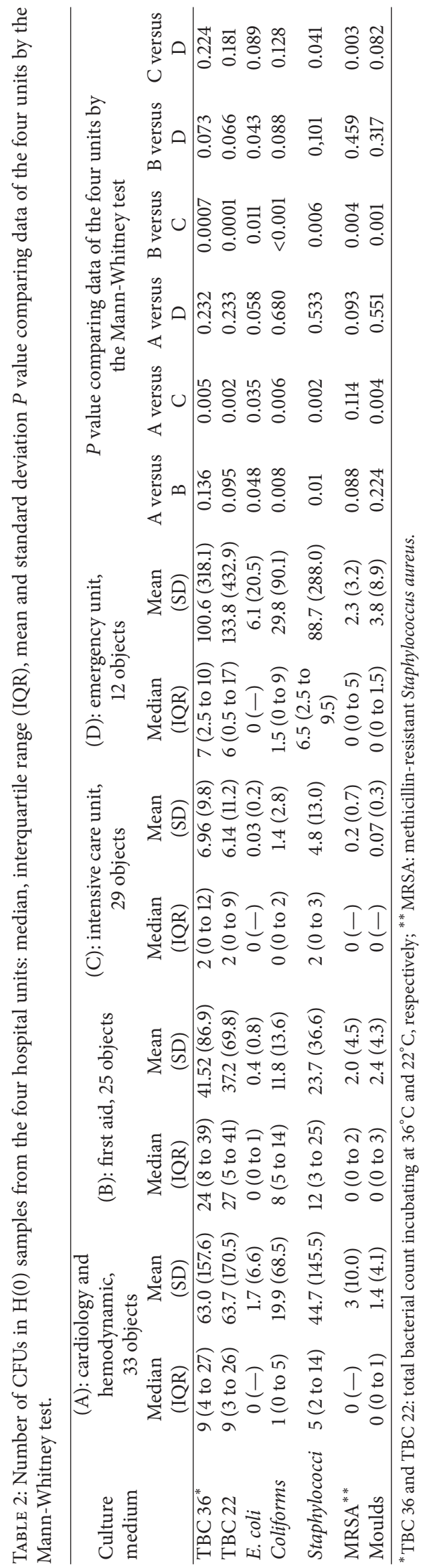


shows $\mathrm{H}(0)$ bacteria/mould contamination counts (mean, standard deviation, median, and interquartile range) for the four units and comparisons between them by the MannWhitney test.

Comparisons of CFUs between computer keyboards plus telephone handsets versus stethoscopes showed significant differences: higher contamination was always found on computer keyboards and telephone handsets than on stethoscopes for moulds $(P=0.002)$. For PCA $36^{\circ} \mathrm{C}$ and PCA $22^{\circ} \mathrm{C}$ we obtained borderline results: $P=0.064$ and $P=0.046$, respectively.

In some cases, comparisons between shared stethoscopes with nonshared ones also showed significant differences in CFUs. We found greater contamination on nurses' and physicians' stethoscopes by PCA $36^{\circ} \mathrm{C}(P=0.015)$ and Staphylococcus spp. $(P=0.016)$; for PCA $22^{\circ} \mathrm{C}$ and MRSA the differences were borderline significant $(P=0.063$ and $P=0.047$, resp.).

\section{Discussion}

Computer keyboards and telephone handsets are commonly found in hospital environments. Several studies have reported contamination of these objects and their possible role in the transmission of HAIs [9-18]. Our study, unlike others, considered all these items together in a hospital setting, as well as comparing units with different organization, patient turnover, medical personnel, and visitors.

In line with our results, other studies also isolated grampositive cocci $[16,17,23-25]$, especially Staphylococcus spp. In our study, 21/35 stethoscopes, 25/27, computer keyboards, and $31 / 37$ telephone handsets were positive for these bacteria. Among $\mathrm{H}(0)$ samples, 10/35, 6/27 and 7/37 were positive for MRSA, respectively. We also isolated several bacterial species that are often the cause of HAIs, such as Coliforms and Enterococcus spp. Acinetobacter spp. was also isolated from one computer keyboard.

After cleaning with the putty containing about 30\% ethyl alcohol, CFUs decreased to zero in most cases and by percentages higher than $96 \%$ for PCA $36^{\circ} \mathrm{C}$ (for all objects); moulds (for computer keyboards); PCA $22^{\circ} \mathrm{C}$, Coliforms and Staphylococcus spp. (for telephone handsets and computer keyboards). Moulds decreased from two to one positive sample in stethoscopes and from 14 to 3 in telephone handsets $(-78,6 \%)$.

Other studies investigating the effectiveness of different sanitizing techniques in reducing microbial contamination of stethoscopes [17, 26-29] looked at products such as ethyl alcohol and ethanol-based cleaners, isopropyl and isopropylbased compounds, and antiseptic soaps, all of which showed the same or less effectiveness than that of the present product $[17,26-28]$. On the contrary, few studies have been conducted on cleaning techniques for telephone handsets and computer keyboards [15], where disinfection is more complex than that for stethoscopes. In fact, liquid compounds may cause aesthetic and functional damage, especially to objects with electronic circuits. The putty product penetrated between and under the keys of keyboards and into the holes of telephone handsets, without wetting the surfaces.

In $\mathrm{H}(0)$ samples our results showed that although the percentage of stethoscopes contaminated by bacteria/moulds was lower than of that telephone handsets and computer keyboards, mean and median CFUs were higher in stethoscope samples (Table 1). This finding is also significant because stethoscopes are much easier to clean. This apparent contradiction (lower contamination percentages but higher numbers of CFUs) could mean that while healthcare personnel are certainly aware of the need to clean/disinfect stethoscopes, the practice is sometimes neglected. Neglecting cleaning and disinfection of telephone handsets and especially computer keyboards can have negative consequences. In fact, although our results confirmed a lower number of CFUs on these objects than on stethoscopes, the percentages of contaminated objects, $\mathrm{H}(0)$ samples, were generally much higher, indicating an aptitude as reservoir of infection. The only Acinetobacter spp. found, albeit a single CFU, was on a computer keyboard and its presence could mean that (i) healthcare staff pay more attention to disinfecting "real" medical devices than other objects; (ii) it is easier to disinfect smooth surfaces, such as stethoscopes, than surfaces with indentations and protrusions, like keyboards; (iii) healthcare staff underestimate the possibility that contamination can occur from objects which are not strictly considered medical devices. It has been demonstrated that MRSA can survive up to seven months on inanimate surfaces, vancomycinresistant germs up to four months, Acinetobacter spp. up to five months, Klebsiella spp. up to thirty months, and spores of Clostridium difficile up to five months [8].

Neglecting the cleaning/disinfection of computer keyboards and the long survival of some bacteria are critical in the role of HAIs. In fact, although healthcare professionals may clean and disinfect their "personal" medical devices, they may still be contaminated by hospital computer keyboards and telephone handsets and transmit infections. Both these devices are used with the hands, which are the top causes of transmission of bacteria $[8,30,31]$. Frequency of disinfection and compliance of hospital personnel could explain the differences we found between the units. For example, "intensive care" was understandably the least contaminated (Table 2), due to strict observance of protocols for aseptic conditions, rooms with few beds, and exclusion of visitors. Moreover, the staff has instructions to clean stethoscopes after each use. Keyboards and telephone handsets are used by staff particularly conscientious about disinfection practices. The "first aid" unit understandably had the highest level of contamination due to fast patient turnover and the greater number of doctors, nurses, and visitors [8]. Here, the staff seemed less sensitive to hygiene, prioritizing "strictly medical activities" and emergency procedures.

Another study [32], involving an intensive care unit, found low bacterial contamination of stethoscopes. These researchers investigated stethoscopes' pathogenic bacterial and skin flora contamination on diaphragms of 46 stethoscopes (22 personal and 24 bedside ones). They found that bedside stethoscopes had pathogenic bacteria and skin flora 
in 2 and 14 samples, respectively, and the personal ones had the same organisms in 3 and 18 samples, respectively.

We also compared microbial contamination of stethoscopes of physicians/nurses and shared stethoscopes and found some differences. We recorded greater contamination on nonshared stethoscopes by PCA $36(P=0.015)$, PCA 22 $(P=0.063)$, Staphylococcus spp. $(P=0.016)$, and MRSA $(P=0.047)$. Healthcare professionals presumably use their own stethoscopes more often than shared ones and do not clean them very often, so that they are more likely to be contaminated. Other reasons for greater contamination of personal stethoscopes could be that shared stethoscopes are subject to established hygiene practices and procedures while personal ones are less likely to be cleaned and disinfected by the owner.

This study involved hospital units with different features and it focused on devices with different structures, surfaces, and functions. These aspects could distort certain comparisons; in particular: (i) the distribution of computer keyboards, telephone handsets, and stethoscopes was not the same in the four units studied, which could influence the number of contaminated samples. However, statistical analysis indicated that these differences in distribution of devices seemed not significant $(P=0.325$, Fisher's exact $X^{2}$ ) and this problem should be avoided; (ii) the swab taken from the half-surface of a computer keyboard is larger than one from half a stethoscope membrane. We therefore expected a greater number of CFUs from keyboards than from stethoscopes but we actually found the opposite. There were, however, more positive samples from computers and telephones than from stethoscopes, and this was expected due the larger surface areas swabbed. In addition while stethoscopes were presumably disinfected more often and more easily than the other devices, their function determined a greater likelihood of contamination.

\section{Conclusions}

In conclusion, our results highlight the importance of proper cleaning/disinfection of medical devices, as well as typical office equipment (computer keyboards and telephone handsets), used by medical staff. All can play a role in bacterial contamination and transmission as a possible cause of HAIs. The disinfecting technique used was effective in reducing/eliminating bacterial load, even on computer keyboards, which were the most complicated of the objects considered to clean/disinfect. The emergence of resistant bacteria, hospitalization of older and critical patients, high turnover of healthcare staff making process standardization difficult, lack of process organization between units and nonobservation of protocols [8] are all areas in need of improvement to prevent HAIs. Environmental disinfection has a central role in the primary prevention of HAIs.

\section{Ethical Approval}

It was not required because patients were not involved.

\section{Conflict of Interests}

The authors declare that there is no conflict of interests.

\section{Disclosure}

The authors declare that the paper is an original work and it has not been published before or submitted for publication to another scientific journal or is being considered for publication elsewhere. They declare that the text has been approved by all coauthors. The authors also understand that should the submitted material be accepted for publication in the journal, they will automatically transfer the copyright to the publisher.

\section{Acknowledgments}

We thank the hospital administration of Siena Teaching Hospital "Le Scotte". The study was conducted under a Master Research and Service Agreement (D.R. 341/2012, signed 6th March 2012, Exhibit 2, 3, and 4 signed 9th July 2012) between the University of Siena and Joker AG/SA which financed the research. Use of the data was authorized by the hospital administration of Siena Teaching Hospital "Le Scotte".

\section{References}

[1] T. C. Horan, M. Andrus, and M. A. Dudeck, "CDC/NHSN surveillance definition of health care-associated infection and criteria for specific types of infections in the acute care setting," American Journal of Infection Control, vol. 36, no. 5, pp. 309-332, 2008.

[2] E. Morales, F. Cots, M. Sala et al., "Hospital costs of nosocomial multi-drug resistant Pseudomonas aeruginosa acquisition," BMC Health Services Research, vol. 12, p. 122, 2012.

[3] I. Ogilvie, H. Khoury, M. M. Goetghebeur, A. C. El Khoury, and C. Giaquinto, "Burden of community-acquired and nosocomial rotavirus gastroenteritis in the pediatric population of Western Europe: a scoping review," BMC Infectious Diseases, vol. 12, article 62, 2012.

[4] R. R. Roberts, R. D. Scott II, R. Cordell et al., "The use of economic modeling to determine the hospital costs associated with nosocomial infections," Clinical Infectious Diseases, vol. 36, no. 11, pp. 1424-1432, 2003.

[5] WHO, "Report on the Burden of Endemic Health CareAssociated Infection Worldwide," pp. 1-34, 2011.

[6] R. M. Klevens, J. R. Edwards, C. L. Richards Jr. et al., "Estimating health care-associated infections and deaths in U.S. Hospitals, 2002," Public Health Reports, vol. 122, no. 2, pp. 160-166, 2007.

[7] ECDC, "Annual epidemiological report Reporting on 2010 surveillance data and epidemic intelligence data," 2012.

[8] P. Manzi, S. Liberatore, and A. Morgante, "Asepsi e disinfezione nel controllo delle infezioni," Progettare per la Sanità, no. 119, pp. $37-40,2010$.

[9] S. A. Alleyne, A. M. Hussain, M. Clokie, and D. R. Jenkins, "Stethoscopes: potential vectors of Clostridium difficile," Journal of Hospital Infection, vol. 73, no. 2, pp. 187-189, 2009.

[10] L. Fenelon, L. Holcroft, and N. Waters, "Contamination of stethoscopes with MRSA and current disinfection practices," Journal of Hospital Infection, vol. 71, no. 4, pp. 376-378, 2009. 
[11] B. Hartmann, M. Benson, A. Junger et al., "Computer keyboard and mouse as a reservoir of pathogens in an intensive care unit," Journal of Clinical Monitoring and Computing, vol. 18, no. 1, pp. 7-12, 2004.

[12] G. Messina, S. Burgassi, C. Russo, E. Ceriale, and L. Mariani, "Indagine sulla contaminazione microbica di stetoscopi, telefoni e tastiere di computer presso una casa di cura," Mondo Sanitario, vol. 19, no. 10, pp. 1-5, 2012.

[13] G. Messina, E. Ceriale, S. Burgassi et al., "Impact of a disinfecting technique on microbial contamination of computer keyboards and telephone handsets," Journal of Hospital Administration, vol. 2, no. 4, pp. 1-6, 2013.

[14] G. Messina, C. Quercioli, S. Burgassi, F. Nistic, A. Lupoli, and N. Nante, "How many bacteria live on the keyboard of your computer?" American Journal of Infection Control, vol. 39, no. 7, pp. 616-618, 2011.

[15] W. A. Rutala, M. S. White, M. F. Gergen, and D. J. Weber, "Bacterial contamination of keyboards: efficacy and functional impact of disinfectants," Infection Control and Hospital Epidemiology, vol. 27, no. 4, pp. 372-377, 2006.

[16] A. Singh and B. Purohit, "Mobile phones in hospital settings: a serious threat to infection," Occupational Health \& Safety, vol. 81, no. 3, pp. 42-44, 2012.

[17] I. Youngster, M. Berkovitch, E. Heyman, Z. Lazarovitch, and M. Goldman, "The stethoscope as a vector of infectious diseases in the paediatric division," Acta Paediatrica, International Journal of Paediatrics, vol. 97, no. 9, pp. 1253-1255, 2008.

[18] M. E. Zuliani Maluf, A. F. Maldonado, M. E. Bercial, and S. A. Pedroso, "Stethoscope: a friend or an enemy?" Sao Paulo Medical Journal, vol. 120, no. 1, pp. 13-15, 2002.

[19] S. Kalenic, A. Budimir, Z. Bosnjak et al., "Guidelines on hand hygiene in health care institutions," Lijecnicki Vjesnik, vol. 133, no. 5-6, pp. 155-170, 2011.

[20] P. Manzi, "Contaminazione controllata," Progettare per la Sanità, no. 113, pp. 38-44, 2009.

[21] CONFARMA, "Study of disinfectant efficacy by the microbe carrier test under simulated conditions of use," 2010.

[22] J. Peacock and S. Kerry, Presenting Medical Statistics From Proposal to Publication, Oxford University Press, 2001.

[23] R. J. Mangi and V. T. Andriole, "Contaminated stethoscopes: a potential source of nosocomial infections," Yale Journal of Biology and Medicine, vol. 45, no. 6, pp. 600-604, 1972.

[24] S. Sengupta, A. Sirkar, and P. G. Shivananda, "Stethoscopes and nosocomial infection," Indian Journal of Pediatrics, vol. 67, no. 3, pp. 197-199, 2000.

[25] M. A. Smith, J. J. Mathewson, I. A. Ulert, E. G. Scerpella, and C. D. Ericsson, "Contaminated stethoscopes revisited," Archives of Internal Medicine, vol. 156, no. 1, pp. 82-84, 1996.

[26] J. S. Jones, D. Hoerle, and R. Riekse, "Stethoscopes: a potential vector of infection?" Annals of Emergency Medicine, vol. 26, no. 3, pp. 296-299, 1995.

[27] P. Lecat, E. Cropp, G. McCord, and N. A. Haller, "Ethanol-based cleanser versus isopropyl alcohol to decontaminate stethoscopes," American Journal of Infection Control, vol. 37, no. 3, pp. 241-243, 2009.

[28] S. Núñez, A. Moreno, K. Green, and J. Villar, "The stethoscope in the emergency department: a vector of infection?” Epidemiology and Infection, vol. 124, no. 2, pp. 233-237, 2000.

[29] H. Saloojee and A. Steenhoff, "The health professional's role in preventing nosocomial infections," Postgraduate Medical Journal, vol. 77, no. 903, pp. 16-19, 2001.
[30] L. Silvestri, A. J. Petros, R. E. Sarginson, M. A. de la Cal, A. E. Murray, and H. K. F. van Saene, "Handwashing in the intensive care unit: a big measure with modest effects," Journal of Hospital Infection, vol. 59, no. 3, pp. 172-179, 2005.

[31] A. E. Yawson and A. A. Hesse, "Hand hygiene practices and resources in a teaching hospital in Ghana," The Journal of Infection in Developing Countries, vol. 7, no. 4, pp. 338-347, 2013.

[32] A. M. Whittington, G. Whitlow, D. Hewson, C. Thomas, and S. J. Brett, "Bacterial contamination of stethoscopes on the intensive care unit," Anaesthesia, vol. 64, no. 6, pp. 620-624, 2009. 


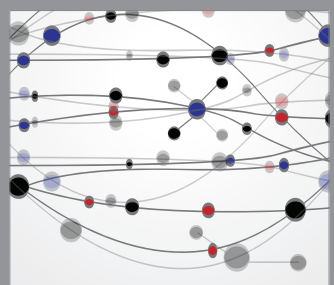

The Scientific World Journal
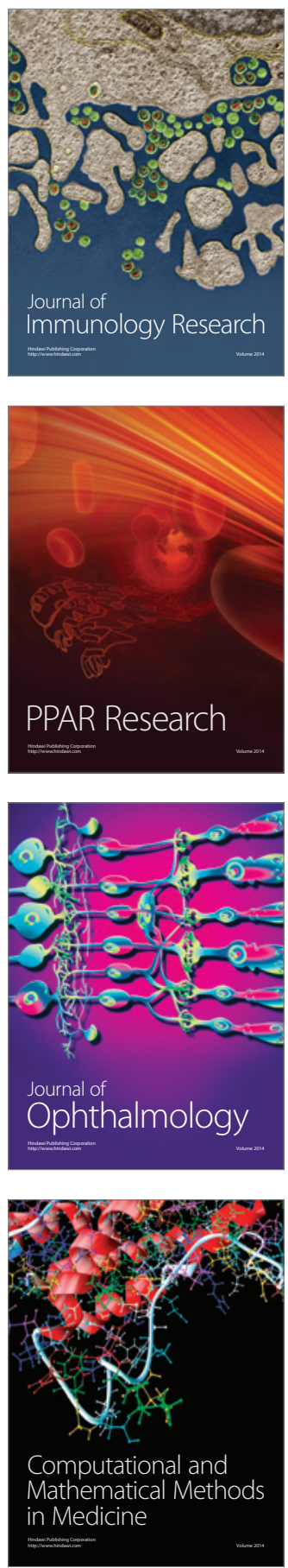

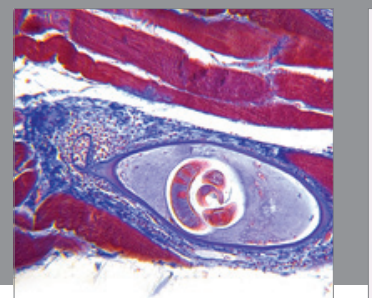

Gastroenterology

Research and Practice
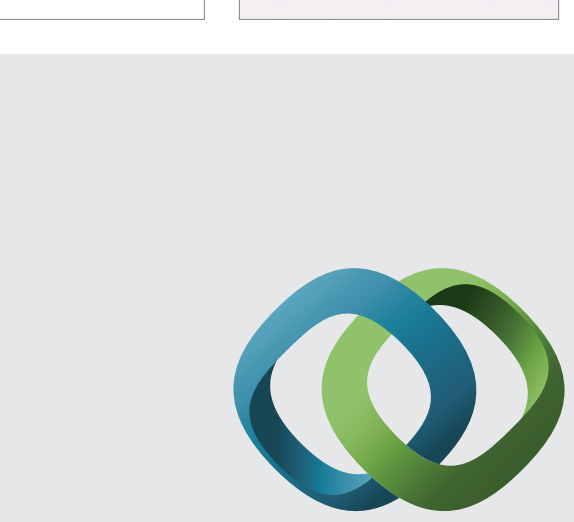

\section{Hindawi}

Submit your manuscripts at

http://www.hindawi.com
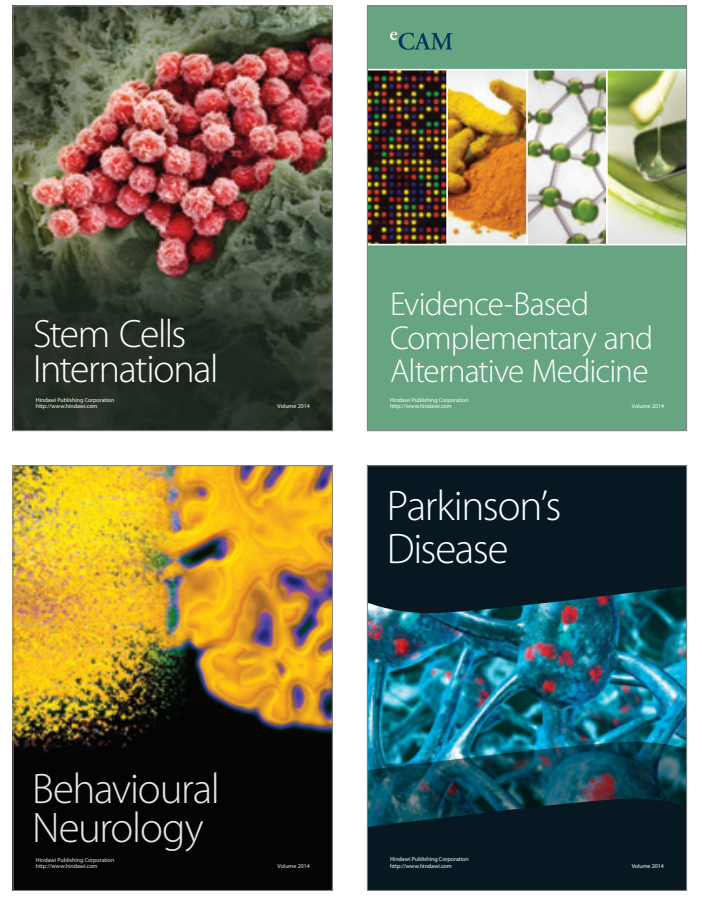
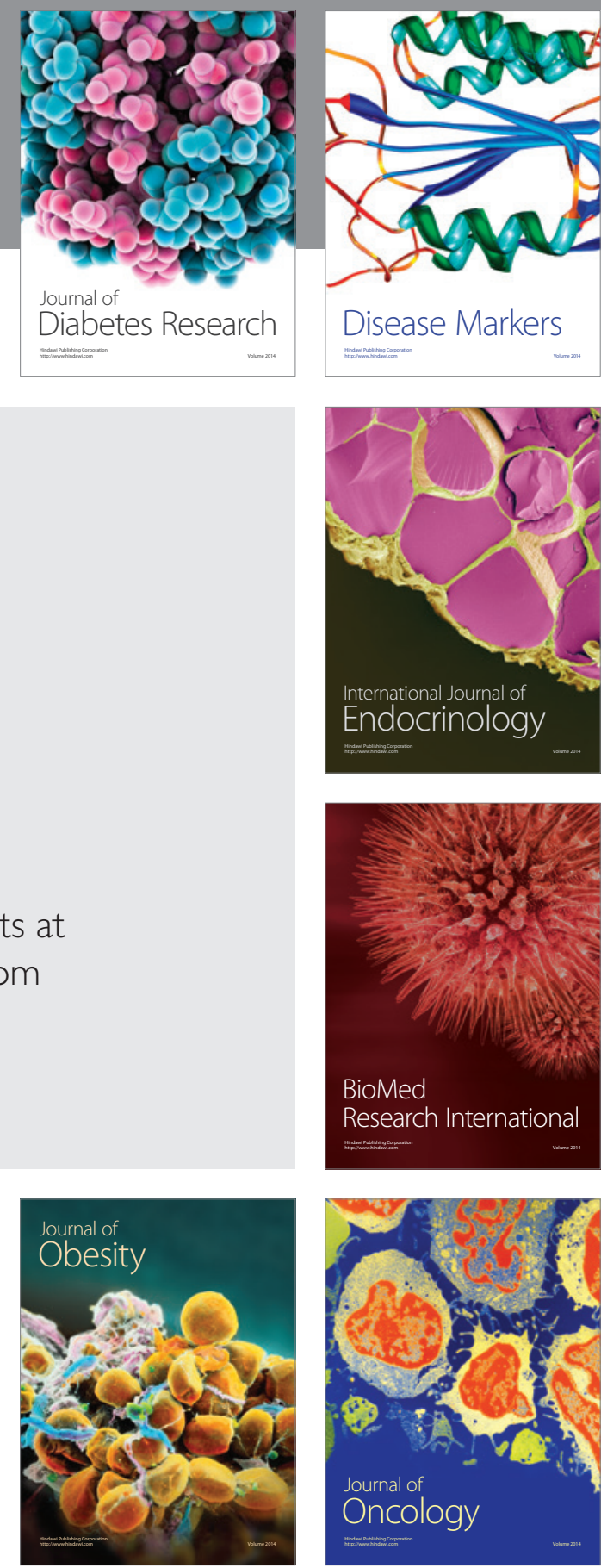

Disease Markers
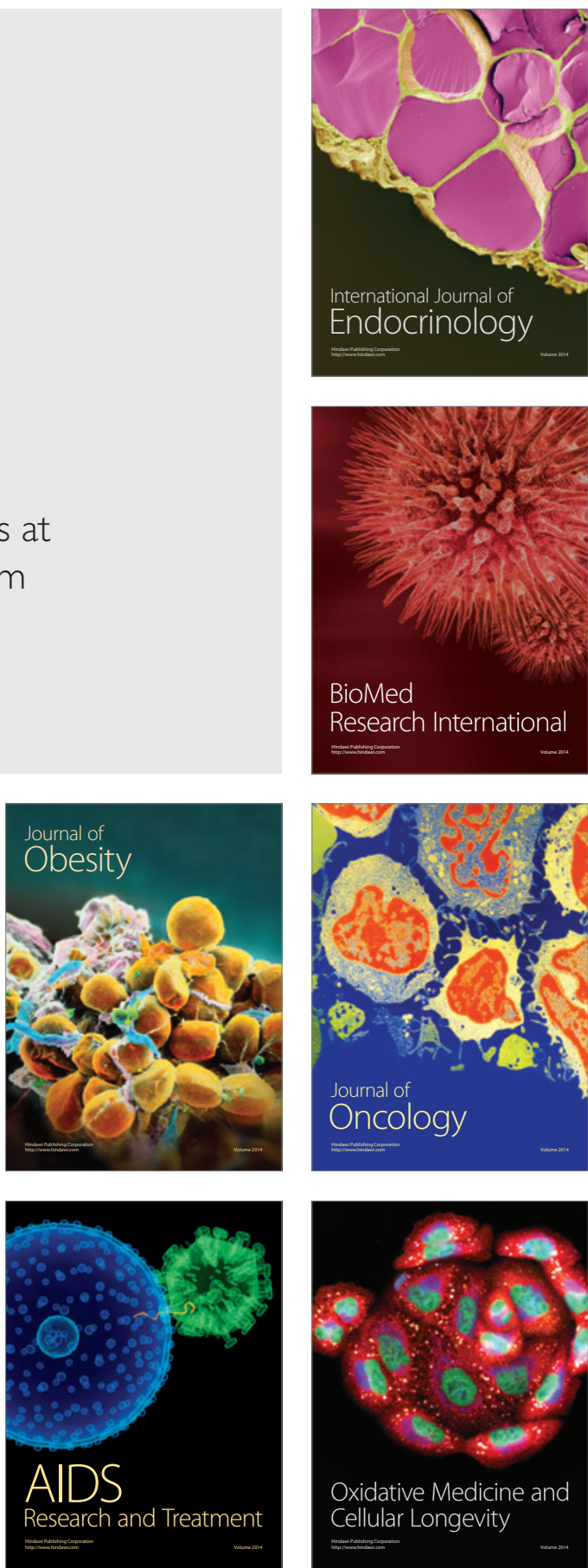